\title{
Clinical value of CYFRA 21.1, carcinoembryonic antigen, neurone-specific enolase, tissue polypeptide specific antigen and tissue polypeptide antigen in the diagnosis of lung cancer
}

\author{
J. Bates*, R. Rutherford*, M. Divilly**, J. Finn**, H. Grimes**, \\ I. O'Muircheartaigh***, J.J. Gilmartin*
}

Clinical value of CYFRA 21.1, carcinoembryonic antigen, neurone-specific enolase, tissue polypeptide specific antigen and tissue polypeptide antigen in the diagnosis of lung cancer. J. Bates, R. Rutherford, M. Divilly, J. Finn, H. Grimes, I. O'Muircheartaigh, J.J. Gilmartin. @ ERS Journals Ltd 1997.

ABSTRACT: In this study we looked at what useful information cytokeratin fragment detected by antibodies BM 19-21 and KS 19-1 (CYFRA 21.1), carcinoembryonic antigen (CEA), neurone-specific enolase (NSE), tissue polypeptide specific antigen (TPS), and tissue polypeptide antigen (TPA) gave when measured prospectively. All patients who were suspected of having lung cancer and who underwent diagnostic bronchoscopy in this hospital between July 1994 and May 1995 were included in the study.

Of 184 patients, 87 were subsequently found to have intrathoracic malignancy, 93 were found to have benign lung disease and four were lost to follow-up.

CYFRA 21.1 was the most efficient marker in differentiating benign from malignant disease, with a sensitivity of $54 \%$ and a positive predictive value of $96 \%$. Thirty seven patients who had a negative bronchoscopy subsequently turned out to have malignant disease. Either CYFRA 21.1 or CEA was elevated in $26(\mathbf{7 0} \%)$ of such patients. Multivariate analysis showed that only CYFRA 21.1 and CEA contributed significantly to the discriminatory power of the data.

We conclude that measurement of cytokeratin fragment detected by antibodies BM 19-21 and KS 19-1 and carcinoembryonic antigen at the time of bronchoscopy significantly increased the diagnostic yield in this population and was especially useful in those patients in whom tumour biopsy was not possible at bronchoscopy. Eur Respir J 1997; 10: 2535-2538.
Depts of *Respiratory Medicine, ${ }^{* *}$ Clinical Biochemistry and $* * *$ Medical Statistics, University College Hospital, Galway, Ireland.

Correspondence: J. Bates

Dept of Respiratory Medicine

University College Hospital

Galway

Ireland

Keywords: Biological tumour markers bronchoscopy

carcinoembryonic antigen

CYFRA 21.1

lung cancer

lung diseases

Received: January 71997

Accepted after revision July 201997
While no tumour marker in lung carcinoma is sufficiently sensitive to justify use as a screening test in asymptomatic patients [1], certain tumour markers have shown promise as complimentary tools in the diagnosis of lung cancer when standard clinical methods fail to establish a diagnosis [2]. In comparative studies cytokeratin fragment detected by antibodies BM 19-21 and KS 19-1 (CYFRA 21.1) has proved to be the marker of choice in non-small cell lung cancer [3-11] and is also of independent prognostic value $[3,12,13]$.

In some studies carcinoembryonic antigen (CEA) has shown greater sensitivity than CYFRA 21.1 for adenocarcinoma [5, 7, 14] and is also of prognostic value [15]. Neurone-specific enolase (NSE) is the marker of choice for small-cell carcinoma [5, 6, 9]. There remains a need for assessment of the analytical performance of CYFRA 21.1 under field conditions [16] as most studies to date have involved retrospective analyses of patients with an established diagnosis.

In this study we looked prospectively at the clinical value of measuring CYFRA 21.1, CEA, NSE, tissue polypeptide specific antigen (TPS), and tissue polypeptide antigen (TPA) in patients who were suspected of having lung carcinoma.

Materials and methods

\section{Patients}

Venous samples were taken from all patients undergoing diagnostic bronchoscopy at the University College Hospital from July 1994 to May 1995 if they were suspected of having lung cancer (184 patients). Samples were taken at the time of bronchoscopy and frozen at $-20^{\circ} \mathrm{C}$ until analysis. Following bronchoscopy, further investigations (including computed tomography (CT) guided fine needle aspiration cytology) were carried out when appropriate and all patients were followed up for a period of at least 2 yrs or until death. Four patients were lost to follow-up (table 1). 
Table 1. - Final diagnosis of 180 patients

\begin{tabular}{lc}
\hline Diagnosis & Patients $\mathrm{n}$ \\
\hline Bronchogenic carcinoma & 70 \\
Squamous cell carcinoma & 38 \\
Small cell carcinoma & 7 \\
Adenocarcinoma & 11 \\
Large cell carcinoma & 14 \\
Untyped tumours & 8 \\
Other intrathoracic malignancy & 9 \\
Benign lung disease & 93 \\
\hline
\end{tabular}

\section{Marker assays}

Enzyme linked immunosorbent assay (ELISA) CYFRA 21.1 and ELISA NSE are solid phase immunoradiometric assays (IRMA) which use $\mathrm{I}^{125}$ as a label, supplied as a kit by CIS Bio International (Gif-sur-Yvette, Cedex, France). CYFRA 21.1 measures a fragment of cytokeratin 19. TPS was measured using a kit (TPS TM ELISA; BEKI Diagnostics, Bromma, Sweden). It uses horseradish peroxidase as a label and is claimed to measure cytokeratin 18. TPA was measured using TPA Prolifigen TPA-M IRMATM kit (Sangtec Medical, Sweden). It measures cytokeratins 8, 18 and 19 .

CEA, a tumour associated glycoprotein, was measured using the Abbot IMX CEA kit (Abbott Laboratories, Abbot Park, Illinois, USA) which is based on a microparticle enzyme immunoassay and uses a fluorescent label. Normal reference ranges were $<3.3 \mathrm{ng} \cdot \mathrm{mL}^{-1}$ for CYFRA $21.1,<7.4 \mathrm{ng} \cdot \mathrm{mL}^{-1}$ for CEA, $<12.5 \mathrm{ng} \cdot \mathrm{mL}^{-1}$ for NSE, $<80 \mathrm{U} \cdot \mathrm{L}^{-1}$ for TPS and $<95 \mathrm{U} \cdot \mathrm{L}^{-1}$ for TPA.

\section{Statistical analysis}

Specificity, sensitivity, positive predictive value (true positive/true positive + false positive), and negative predictive value (true negative/true negative + false negative) were calculated using Bayes' theorem. Values for CYFRA 21.1, CEA, NSE and TPS were log transformed before calculation of correlation coefficients as none of the markers showed a normal distribution. Receiver operating characteristic (ROC) curves were constructed for each marker by calculating specificity and sensitivity values over a range of cut-off points and area under the curve was calculated using the program ROC.xlm v1.1 (author Gy. Gorog, H- 1116 Budapest).

The multivariate statistical technique of linear discriminant analysis (LDA) was applied using the five markers, as this technique can often improve the performance of diagnostic test combinations [17]. As classical LDA is optimal when the underlying data follow a normal distribution, a log transformation was applied to CYFRA 21.1 and CEA and this led to a significant improvement in diagnostic performance. Cross-validation of the LDA was also applied to the data.

\section{Results}

CYFRA 21.1 was the most efficient marker in differentiating benign from malignant disease in this population with a sensitivity of $54 \%$, specificity of $98 \%$ and positive predictive value of $96 \%$ (table 2). Sensitivity was highest for adenocarcinoma but patients with adenocarcinoma had more advanced disease than other histological types. TPS showed low specificity for malignancy and high levels were seen in many patients with inflammatory lung conditions (table 2).

Levels of this marker were significantly higher in infective (pneumonia and tuberculosis) versus noninfective benign lung disease (Mann Whitney U-test, $\mathrm{p}=$ 0.002) as were levels of TPA (Mann Whitney U-test, $\mathrm{p}=0.045$ ) and CYFRA 21.1 (Mann Whitney U-test, $\mathrm{p}=$ $0.045)$

One hundred and thirty patients had a negative bronchoscopy. Of these, 37 subsequently turned out to have malignancy (table 3). CYFRA 21.1 was elevated in 24

Table 3. - Incidence of negative bronchoscopy amongst 130 patients

\begin{tabular}{lcc}
\hline & $\begin{array}{c}\text { Pegative } \\
\text { Patients } \\
\mathrm{n}\end{array}$ & $\begin{array}{c}\text { bronchoscopy } \\
\mathrm{n}\end{array}$ \\
\hline Non-small cell carcinoma & 63 & 22 \\
Small cell carcinoma & 7 & 0 \\
Untyped tumours & 8 & 8 \\
Other intrathoracic malignancy & 9 & 7 \\
Benign lung disease & 93 & 93 \\
\hline
\end{tabular}

Table 2. - Sensitivity, specificity, and positive predictive value of tumour markers for malignancy

\begin{tabular}{|c|c|c|c|c|c|c|}
\hline \multirow[t]{2}{*}{ Marker } & \multicolumn{2}{|c|}{ Sensitivity } & \multicolumn{2}{|c|}{ Specificity } & \multicolumn{2}{|c|}{$\begin{array}{c}\text { Positive } \\
\text { predictive value }\end{array}$} \\
\hline & $\%$ & $\mathrm{n}$ & $\%$ & $\mathrm{n}$ & $\%$ & $\mathrm{n}$ \\
\hline CYFRA $21.1>3.3 \mathrm{ng} \cdot \mathrm{mL}^{-1}$ & 54 & $47 / 87$ & 98 & $91 / 93$ & 96 & $47 / 49$ \\
\hline $\mathrm{CEA}>7.4 \mathrm{ng} \cdot \mathrm{mL}^{-1}$ & 31 & $27 / 87$ & 96 & $89 / 93$ & 87 & $27 / 31$ \\
\hline $\mathrm{NSE}>12.5 \mathrm{ng} \cdot \mathrm{mL}^{-1}$ & 23 & $20 / 87$ & 92 & $86 / 93$ & 74 & $20 / 27$ \\
\hline TPS $>80 \mathrm{U} \cdot \mathrm{L}^{-1}$ & 64 & $56 / 87$ & 69 & $64 / 93$ & 66 & $56 / 85$ \\
\hline TPA $>95 \mathrm{U} \cdot \mathrm{L}^{-1}$ & 76 & $66 / 87$ & 87 & $81 / 93$ & 85 & $66 / 78$ \\
\hline CYFRA 21.1/CEA* & 64 & $56 / 87$ & 94 & $87 / 93$ & 90 & $56 / 62$ \\
\hline CYFRA 21.1/CEA** & 75 & $65 / 87$ & 91 & $85 / 93$ & 89 & $65 / 73$ \\
\hline
\end{tabular}

CYFRA 21.1: cytokeratin fragment detected by antibodies BM 19-21 and KS 19-1. CEA: carcinoembryonic antigen; NSE: neurone-specific enolase; TPS: tissue polypeptide specific antigen; TPA: tissue polypeptide antigen. *: denotes testing in parallel (i.e. either CYFRA 21.1 or CEA elevated); **: using the linear discriminated analysis rule ln (CYFRA 21.1) + 0.24 ln (CEA) $>1$. 
Table 4. - Sensitivity of tumour markers in 130 patients with a negative bronchoscopy

\begin{tabular}{lcccccc}
\hline & Sensitivity & \multicolumn{2}{c}{$\begin{array}{c}\text { Positive } \\
\text { predictive } \\
\text { value }\end{array}$} & \multicolumn{2}{c}{$\begin{array}{c}\text { Negative } \\
\text { predictive } \\
\text { value }\end{array}$} \\
& $\%$ & $\mathrm{n}$ & $\%$ & $\mathrm{n}$ & $\%$ & $\mathrm{n}$ \\
\hline CYFRA 21.1 & 65 & $24 / 37$ & 92 & $24 / 26$ & 88 & $91 / 104$ \\
CEA & 30 & $11 / 37$ & 73 & $11 / 15$ & 77 & $89 / 115$ \\
CYFRA 21.1/CEA* & 70 & $26 / 37$ & 81 & $26 / 32$ & 89 & $87 / 98$ \\
\hline
\end{tabular}

CYFRA 21.1: cytokeratin fragment detected by antibodies BM 19-21 and KS 19-1. *: tested in parallel.

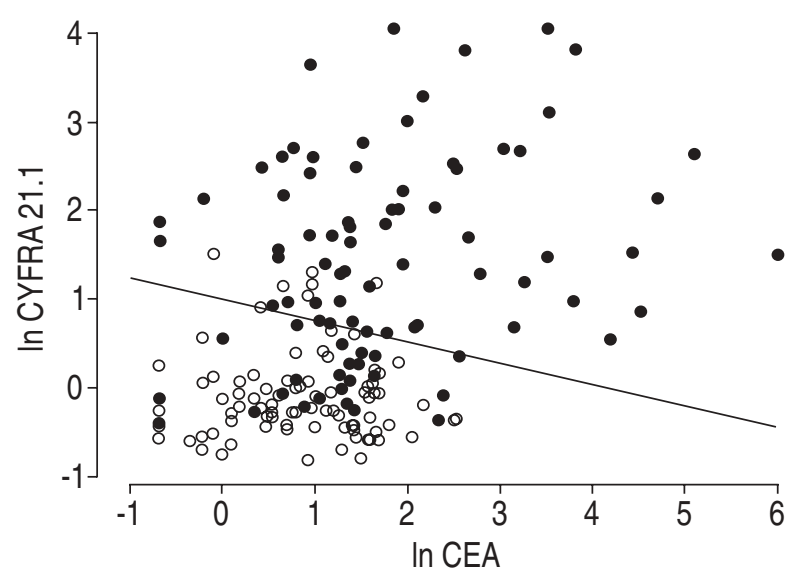

Fig. 1. - Linear discriminant analysis. Each patient is represented by a point in the (cytokeratin fragment detected by antibodies BM 19-21 and KS 19-1 (CYFRA 21.1), carcinoembryonic antigen (CEA)) plane. The line shown best discriminates the two groups into malignant disease (above the line) and benign disease (below the line). ln: natural log. o: benign; $\bullet$ : malignant.

(65\%) of these patients and elevation of either CYFRA 21.1 or CEA was seen in $26(70 \%)$ (combined specificity for malignant disease $94 \%$ ) (table 4). Negative predictive value for malignant disease of a combination of bronchoscopy with CYFRA 21.1 and CEA was $89 \%$ as against $72 \%$ with bronchoscopy alone.

ROC curves calculated for the five markers also suggested that CYFRA 21.1 was the marker of choice in this population. The area under the CYFRA ROC curve was 0.88 as compared to 0.66 for CEA and 0.59 for NSE indicating the higher diagnostic accuracy of CYFRA.

LDA showed that, of the five markers, only CYFRA 21.1 and CEA contributed significantly to the discriminatory power of the data. Log transformation of these two markers led to a significant improvement in diagnostic performance. The rule produced by LDA was: patient positive if natural log (ln) (CYFRA 21.1) + 0.24 In $($ CEA) $>1$. When cross validation was applied to the data, the effect on the sensitivity, specificity and positive predictive value of this LDA rule was negligible (table 2, fig. 1).

As expected the cytokeratin markers (especially CYFRA 21.1 and TPA) showed the closest inter-marker correlation (table 5).

\section{Discussion}

Tumour markers have five possible applications: screening; monitoring disease progress; prognostic indicators; detecting relapse; and diagnostic tools [1]. Definitive diagnosis of lung cancer (i.e. histological examination of part of the tumour mass) involves an invasive procedure (e.g. bronchoscopy and biopsy or fine needle aspiration cytology). In some patients it may not be possible to obtain biopsy material, and in these cases tumour marker levels can be useful.

In this population of 180 patients CYFRA 21.1 and CEA in addition to bronchoscopy increased the negative predictive value for malignancy to $89 \%$ compared to $72 \%$ with bronchoscopy alone and these two markers detected $70 \%$ of the 37 tumours not detected by bronchoscopy. These findings confirm the suggestion that tumour markers are useful diagnostically when histological diagnosis is difficult $[2,16,18]$.

CYFRA 21.1 in this as well as in other studies [311] proved to be the marker of choice for non-small cell carcinoma, especially squamous cell carcinoma and CEA gave additional information to CYFRA 21.1 as has also been found previously [8].

PAONE and co-workers $[19,20]$ have previously shown that analysis of CYFRA 21.1 and NSE provides good discrimination between non-small cell and small cell lung cancer with a reliability of $93 \%$. The present study shows that CYFRA 21.1 and CEA can be used to provide accurate diagnosis of lung cancer in patients for whom bronchoscopy fails to establish a diagnosis. These findings suggest that a diagnosis of non-small cell or small cell lung cancer may be made with some degree of accuracy using tumour markers alone when a tissue diagnosis is not available. Of the tumour markers used in this study, CYFRA 21.1 and CEA gave the most diagnostic information.

We would, therefore, suggest that measurement of these markers is of value in all patients suspected of having lung carcinoma who have a negative bronchoscopy. The results may indicate a diagnosis in those unfit for further intervention and in those for whom further investigations fail to establish a tissue diagnosis.

Table 5. - Correlation between log transformed tumour markers

\begin{tabular}{lllll}
\hline & CYFRA 21.1 & CEA & NSE & TPS \\
\hline CYFRA 21.1 & 1 & $0.419 * * *$ & 0.113 & $0.632 * * *$ \\
CEA & $0.419 * * *$ & 1 & 0.066 & $0.390 * * *$ \\
NSE & 0.113 & 0.066 & 1 & 0.095 \\
TPS & $0.632 * * *$ & $0.390 * * *$ & 0.095 & $0.471 * * *$ \\
TPA & 0.873 & $0.471 * * *$ & 0.147 & 0.147 \\
\hline
\end{tabular}

$* * *: \mathrm{p}<0.001$. For definitions of abbreviations see legend to table 2 . 


\section{References}

1. Bates SE. Clinical applications of serum tumour markers. Ann Intern Med 1991; 115: 623-638.

2. Bergman B, Brezicka FT, Engström CP, Larsson S. Clinical usefulness of serum assays of neuron-specific enolase, carcinoembryonic antigen and CA-50 antigen in the diagnosis of lung cancer. Eur J Cancer 1993; 29A: 198-202.

3. Weiskopf B, Demangeat C, Purohit A, et al. CYFRA 21.1 as a biologic marker of non-small cell lung cancer: evaluation of sensitivity, specificity, and prognostic role. Chest 1995; 108(1): 163-169.

4. Takada M, Masuda N, Matsuura E, et al. Measurement of cytokeratin 19 fragments as a marker of lung cancer by CYFRA 21.1 enzyme immunoassay. $\mathrm{Br} \mathrm{J}$ Cancer 1995; 71(1): 160-165.

5. Ebert W, Dienemann H, Fateh-Moghadam A, et al. Cytokeratin fragment CYFRA 21.1 compared with carcinoembryonic antigen, squamous cell carcinoma antigen and neuron-specific enolase in lung cancer: results of an International multicentre study. Eur J Clin Chem Clin Biochem 1994; 32(3): 189-199.

6. Stieber P, Dienemann H, Hasholzner U, et al. Comparison of cytokeratin fragment 19 (CYFRA 21.1), tissue polypeptide antigen (TPA) and tissue polypeptide specific antigen (TPS) as tumour markers in lung cancer. Eur $J$ Clin Chem Clin Biochem 1993; 31(10): 689-694.

7. Lai RS, Hsu HK, Lu JY, Ger LP, Lai NS. CYFRA 21.1 enzyme-linked immunosorbent assay: evaluation as a tumour marker in non-small cell lung cancer. Chest 1996; 109(4): 995-1000.

8. Murakai M, Tohda Y, Iwanga T, Uejima H, Nagasaka Y, Nakajima S. Assessment of serum CYFRA 21.1 in lung cancer. Cancer 1996; 77(7): 1274-1277.

9. Stieber P, Hasholzner U, Bodenmuller H, et al. CYFRA 21.1: a new marker in lung cancer. Cancer 1993; 72(3): 707-713

10. Pujol JL, Grenier J, Ray P, Gautier V, Aouta MD, Michel FB. CYFRA 21.1: a new marker of epidermoid cancer of the bronchi: comparison with 3 other markers. Presse Medicale 1993; 22(22): 1039-1042.
11. Rastel D, Ramaioli A, Cornillie F, et al. CYFRA 21.1, a sensitive and specific new tumour marker for squamous cell lung cancer: report of the first European multicentre evaluation. Eur J Cancer 1994; 30A: 601606.

12. Pujol JL, Grenier J, Parrat E, et al. Cytokeratins as serum markers in lung cancer: a comparison of CYFRA 21.1 and TPS. Am J Respir Crit Care Med 1996; 154 (3 Pt 1): 725-733.

13. Takei Y, Minato K, Tsuchiya S, et al. CYFRA 21.1: an indicator of survival and therapeutic effect in lung cancer. Oncology 1997; 54(1): 43-47.

14. van der Gaast A, Schoenmakers CHH, Kok TC, Blijenberg BG, Cornillie F, Splinter TAW. Evaluation of a new tumour marker in patients with non-small-cell lung cancer. Brit J Cancer 1994; 69: 525-528.

15. Spiridonidis $\mathrm{CH}$, Laufman LR, Stydnicki KA, et al. Decline of post-treatment tumour marker levels after therapy of non-small cell lung cancer: a useful outcome predictor. Cancer 1995; 75(7): 1586-1593.

16. Ebert W, Bodenmuller H, Holzel W. CYFRA 21.1: clinical applications and analytical requirements. Scand J Clin Laboratory Investigation 1995; (Suppl.) 221: 72-80.

17. Ferriss JB, Neville AM, Brown JJ, et al. Hypertension with aldosterone excess and low plasma-renin: preoperative distinction between patients with and without adrenocortical tumour. Lancet 1970; 2: 995-1000.

18. Ebert W, Muley T, Drings P. Does the assessment of serum tumour markers in patients with lung cancer aid in the clinical decision making process? Anticancer Research 1996; 16(4B): 2161-2168.

19. Paone G, De Angelis G, Munno R, et al. Discriminant analysis on small ceil lung cancer and non-small-cell lung cancer by means of NSE and CYFRA 21.1. Eur Respir J 1995; 8: 1136-1140.

20. Paone G, De Angelis G, Portalone L, et al. Validation of an algorithm to differentiate small cell lung cancer from non-small cell lung cancer patients by means of a tumour marker panel: analysis of the errors. Br J Cancer 1997; 75(3): 448-450. 